\title{
Seasonality of birth in adult type 2 diabetic patients in three Ukrainian regions
}

\author{
A. M. Vaiserman - M. D. Khalangot • B. Carstensen • \\ M. D. Tronko • V. I. Kravchenko • V. P. Voitenko • \\ L. V. Mechova • N. M. Koshel • P. E. Grigoriev
}

Received: 7 August 2009 /Accepted: 11 August 2009/Published online: 12 September 2009

(C) Springer-Verlag 2009

Keywords Birth cohorts · Early-life conditions .

Month-of-birth pattern · Type 2 diabetes

To the Editor: Epidemiological studies have repeatedly shown a link between poor fetal growth and increased risk of developing type 2 diabetes [1]. Month of birth is a good instrument for the assessment of effects of early growth on adult health independent of life-course factors. This is true because in decades past there were important seasonal differences in nutrition, especially in developing countries such as Ukraine. These differences in access to high-quality food supply can potentially influence intrauterine growth, depending on the month of gestation [2]. Other possible triggering factors for developing type 2 diabetes, such as production of vitamin D [3] and outdoor temperature [4], also tend to change seasonally.

A. M. Vaiserman - V. P. Voitenko $\cdot$ L. V. Mechova $\cdot$ N. M. Koshel Laboratory of Mathematical Modelling of Aging Processes, Institute of Gerontology,

Kiev, Ukraine

M. D. Khalangot $(\varangle) \cdot$ M. D. Tronko $\cdot$ V. I. Kravchenko Department of Epidemiology,

Institute of Endocrinology and Metabolism,

Vyshgorodska 69,

Kiev 04114, Ukraine

e-mail: nikhalangot@ukr.net

B. Carstensen

Steno Diabetes Center,

Gentofte, Denmark

P. E. Grigoriev

Tavrida Humanitarian Ecological Institute,

Simferopol, Ukraine
Seasonal pattern of birth in type 1 diabetic children and adolescents was repeatedly described around the world, including our recent study in Ukraine [5]. In contrast, the seasonality of birth in type 2 diabetic patients was previously reported only in a few small-sample studies, e.g. in 155 African-American type 2 diabetic adolescent [6] and 282 adult patients in the Netherlands [7]. To study whether abnormal seasonality of birth exists in middle- to old-aged type 2 diabetic patients in Ukraine, we compared the month-of-birth patterns in type 2 diabetic patients in three large Ukrainian regions with those in general populations.

Information on date of birth, sex and year of diagnosis was extracted from the nationwide primary-care-based Ukrainian diabetes mellitus register created in 2000 in the Institute of Endocrinology, Kiev, Ukraine. The definition of type 2 diabetes was based on onset after 39 years of age, irrespective of the type of treatment.

Cases were identified from the three regional diabetes registers with high completeness of ascertainment: Chernigiv (100\%), Kherson (99.7\%) and Rivne (86.2\%). These registers cover $7.4 \%$ of the total Ukraine population. A female excess was evident in all three registers. Cases were all people alive with diagnosis of type 2 diabetes as of 1 January 2008, and who were diagnosed at age 40 or later. Only people born before 1 January 1960 were included; thus all cases included were at least 48. In total, 17,510 male and 34,704 female type 2 diabetic patients were finally included in the study. Reference populations were based on the Ukraine census 2001 depersonalised data. These populations included people who had been born during the same period and were residents of the same regions: Chernigiv, 247,253 men and 369,357 women; Kherson, 208,944 men and 291,802 women; Rivne, 189,887 men and 260,674 women. 


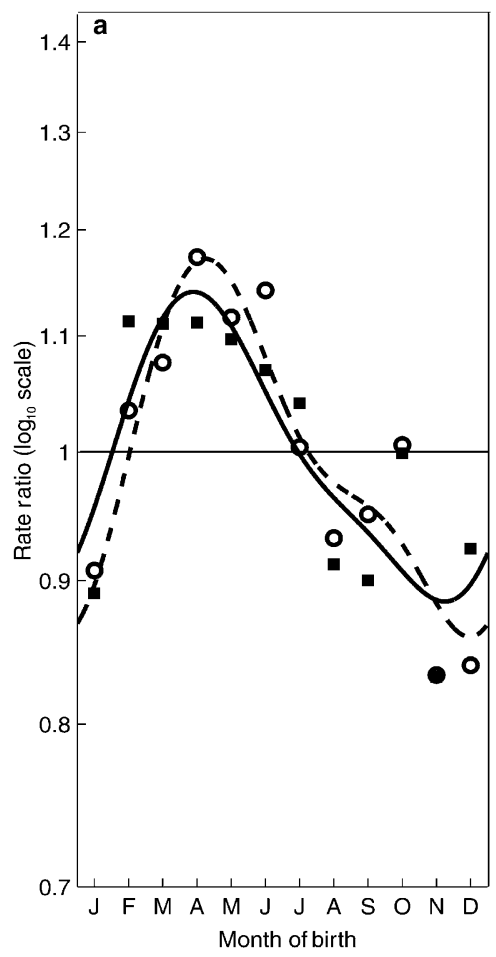

Fig. 1 Effect of month of birth on the risk of developing type 2 diabetes. a The overall effect for men (solid line and black squares) and women (dashed line and white circles). $\mathbf{b}-\mathbf{g}$ Analyses subdivided by sex and regions. Chernigiv men $(n=6,411)(\mathbf{b})$; Kherson men $(n=6,145)(\mathbf{c})$;

Seasonal birth patterns in diabetes prevalence were estimated using logistic regression with second-order harmonic terms. All tests were performed as likelihood ratio tests. Analyses were also done by birth cohort (1920 1929, 1930-1939, 1940-1949 and 1950-1959). More details of the statistical analysis can be found in our previous paper [5].

Seasonality of birth was evident in type 2 diabetic patients [male: peak on 12 April, nadir on 22 November, likelihood ratio $\chi^{2}(4)=132.82, p<0.0001$; female: peak on 22 April, nadir on 15 December, $\left.\chi^{2}(4)=347.43, p<0.0001\right]$. Similar patterns of birth were obtained for all regions studied and all birth cohorts over the study period (Fig. 1). Surprisingly, the month-of-birth pattern obtained in the present study for middle- to old-aged type 2 diabetic patients is similar to that previously found for type 1 diabetic patients in Ukraine [5]. Our findings are consistent with studies in the USA [6] and in the Netherlands [7], showing that seasonal patterns are similar for type 1 and type 2 diabetes.

In the study population, individuals born in April experienced fetal life largely in the nutritionally marginal months from late autumn to early spring, and passed the first postnatal months in a season of relative plenty. These individuals were found to have increased risk of type 2 diabetes. In contrast, a decreased risk was found for those
Rivne men $(n=4,954)(\mathbf{d})$; Chernigiv women $(n=12,183)(\mathbf{e})$, Kherson women $(n=13,593)(\mathbf{f})$, Rivne women $(n=8,928)(\mathrm{g})$. In each of the panels, the estimated patterns subdivided by birth cohort are drawn as thin lines; the overall effects are drawn as the thick lines

born in November-December. In this group, fetal development in a nutritionally favourable season would have been followed by early infancy in a season of relative shortage (winter-spring). The first scenario has a higher risk for type 2 diabetes development than the second one.

A possible limitation of the study is that the reliability of the Ukrainian diabetes register has not yet been sufficiently assessed. Further research is needed to determine the reliability of the register data and to clarify the mechanisms causing similar seasonality of birth in type 1 and type 2 diabetic patients.

Acknowledgements We thank all of the Ukrainian primary care doctors who supplied clinical data on their patients to the National Diabetes Mellitus Registry.

Duality of interest The authors declare that there is no duality of interest associated with this manuscript.

\section{References}

1. Jones RH, Ozanne SE (2009) Fetal programming of glucose-insulin metabolism. Mol Cell Endocrinol 297:4-9

2. Watson PE, McDonald BW (2007) Seasonal variation of nutrient intake in pregnancy: effects on infant measures and possible 
influence on diseases related to season of birth. Eur J Clin Nutr 61:1271-1280

3. Doró P, Grant WB, Benko R, Matuz M, Tóth T, Soós G (2008) Vitamin $\mathrm{D}$ and the seasonality of type 2 diabetes. Med Hypotheses 71:317-318

4. Lawlor DA, Davey Smith G, Mitchell R, Ebrahim S (2004) Temperature at birth, coronary heart disease, and insulin resistance: cross sectional analyses of the British women's heart and health study. Heart 90:381-388
5. Vaiserman A, Carstensen B, Voitenko V et al (2007) Seasonality of birth in children and young adults (0-29 years) with type 1 diabetes in Ukraine. Diabetologia 50:32-35

6. Grover V, Lipton RB, Sclove SL (2004) Seasonality of month of birth among African American children with diabetes mellitus in the City of Chicago. J Pediatr Endocrinol Metab 17:289-296

7. Jongbloet PH, van Soestbergen M, van der Veen EA (1988) Monthof-birth distribution of diabetics and ovopathy: a new aetiological view. Diabetes Res 9:51-58 